\title{
Regulation of Tumor Angiogenesis and Choroidal Neovascularization by Endogenous Angioinhibitors

\author{
Venugopal Gunda ${ }^{1}$ and Yakkanti A Sudhakar ${ }^{2 *}$
}

${ }^{1}$ The Eppley Institute for Cancer and Allied Diseases, University of Nebraska Medical Center, Omaha, NE 68198, USA

${ }^{2}$ Cell Signaling Laboratory, Bioscience Division, Center for Cancer and Metabolism, Stanford Research Institute (SRI) International, Menlo Park, CA 94025, USA

\begin{abstract}
Angiogenesis is the process of neovascularization from parent blood vessels, which is a prerequisite for many physiological and pathological conditions and is regulated by a balance between endogenous angioinhibitors and angioactivators or angiogenic factors. Imbalance between angioinhibitors and angioactivators is associated with neovascularization capacity during progression of tumor development and Choroidal Neovascularization (CNV). Normalization of pathological angiogenesis is considered as an alternative strategy to prevent the tumor growth in cancer progression or retinal damage in CNV. Various angioinhibitors are being identified and evaluated for their pathological angiogenesis regulation, of which endogenous angioinhibitors are one class derived either from extra cellular matrix or from non-extra cellular matrix of human origin. Endogenous angioinhibitors are gaining much significance as they interact with proliferating endothelial cells by binding to distinct integrins and non-integrin receptors, regulating different intracellular signaling mechanisms leading to inhibition of choroidal neovascularization and tumor growth. This review will focus on endogenous angioinhibitors and their receptor(s) mediated angioinhibitory signaling, which are of major concern in angiogenesis and their clinical and pharmaceutical implications.
\end{abstract}

Keyword: Angiogenesis; Endothelial Progenitor Cells (EPCs); Vasoinhibins; Pigment epithelium derived factor (PEDF)

\section{Introduction}

\section{Angiogenesis}

Angiogenesis is the sprouting of capillaries to form new vascular network for maintaining the supply and exchange of metabolites, hormones, and gases required for tissue growth or repair. It is the major process of de-novo vascular growth or neovascularization in adult tissues for wound healing, inflammatory responses and endometrial vascular growth during female reproductive cycles [1]. Blood capillaries are constituted by a single layer of Endothelial Cells (ECs), surrounded and supported by Extracellular Matrix (ECM) called Vascular Basement Membrane (VBM) and pericytes [2]. This simple histological organization facilitates the exchange of metabolites and regulatory factors with the surrounding tissues. Angiogenic factors promote angiogenesis which is initiated with the proliferation and migration of ECs, remodeling of VBM by ECs through secretion of proteases, differentiation of ECs into tip and stalk cells, lumen development, ECM secretion and finally vessel anastomosing into functional capillaries [3]. These angiogenic factors stimulate and maintain the vascular growth necessary in both physiological and pathological angiogenesis.

\section{Pathological angiogenesis in tumors and ocular tissues}

Angiogenesis during tumor growth and neovasculrization in ocular tissues involves the stimulation by angiogenic factors, which are in relatively higher levels in both these conditions. Tumor neovasculrization is maintained by the secretion of angiogenic factors either by the tumor cells themselves or by the cells recruited into tumor microenvironment by the differentiation of Endothelial Progenitor Cells (EPCs), through vasculogenesis [4]. Similarly, ocular neovascularization arises from the pre-existing vasculature in eye, through the angiogenic switch stimulated by the angiogenic factors secreted within ocular tissues or by the cells recruited through vasculogenesis.

\section{Tumor angiogenesis}

Tumor progression is an abnormal tissue growth comprising of transformed cancerous cells with altered genetic and proteomic patterns. The oncogenic genetic and physiological abberrations in tumor cells confer them with uncontrolled proliferative capacity, which demands a continuous supply of oxygen and removal of the metabolic wastes, to compensate the enhanced growth. Therefore, additional vascular supply is essential for the developing tumors as reported by Judah Folkman group at Harvard University; showing that the tumor growth is not supported beyond a few millimeters in size without angiogenesis [5]. However, tumor vasculature exhibits differences compared to normal vasculature with respect to the fenestrated tumor endothelium comprised of ECs and tumor cells, few pericytes, convoluted vasculature and incomplete or leaky VBM in tumor vessels [6].

\section{Age related macular degeneration and choroidal neovascularization}

In the eye, ocular tissues have an organized vascular supply confined to choroid, hyaloid and inner layers of retina, maintaining the supply and homeostasis in healthy condition $[7,8]$. However, abnormal vascular growth petterns such as Choroidal Neovascularization (CNV) and retinal angiogenesis are evident in pathological proliferative

*Corresponding author: Yakkanti Akul Sudhakar,Senior Scientist/Associate Director: Center for Cancer \& Metabolism, Cell Signaling Laboratory, Bioscience Division, SRI International, 333 Ravenswood Avenue, Menlo Park, California 94025-3493, Tel: (650) 859-3262; Fax: (650) 859-3153; E-mail: sudhakar.yakkanti@sri.com

Received June 27, 2013; Accepted July 02, 2013; Published July 04, 2013

Citation: Gunda V, Sudhakar YA (2013) Regulation of Tumor Angiogenesis and Choroidal Neovascularization by Endogenous Angioinhibitors. J Cancer Sci Ther 5: 417-426. doi:10.4172/1948-5956.1000417

Copyright: @ 2013 Gunda V, et al. This is an open-access article distributed under the terms of the Creative Commons Attribution License, which permits unrestricted use, distribution, and reproduction in any medium, provided the original author and source are credited. 
diabetic retinopathy, retinopathy of prematurity and Age Related Macular Degeneration (AMD). CNV of AMD is of serious concern as the leading cause of blindness observed with aging in the modern world. The clinical manifestation of AMD includes detachment of retina with the degeneration of macula (the central zone of retina opposite to the lens), leading to the partial or complete loss of vision. There are two types of AMD; "Wet" or Neovascular and "Dry" or Atrophic. There is no cure for AMD, but new treatments are available for the Wet form of the disease. Wet form of AMD is a pathological condition, which involves the growth of new blood vessels from the choroid that lies underneath the retina leading to the formation of leaky blood vessels (Choroidal Neovascularization/CNV) with subsequent detachment of the retina [8-10]. Dry form of AMD is most common type of macular degeneration and affects $90 \%$ of the people who have the condition. In the Dry form of AMD, there is a degeneration of the layer of Retinal Pigment Epithelial Cells (RPE) in the macula. These RPE cells support the light sensitive photoreceptor cells that are critical to vision. The photoreceptors (rods and cones) gather the images and send them to the brain, where vision takes place. The death or degeneration of RPE cells is called atrophy. Dry form of AMD is characterized by the presence of drusen (dots of yellow crystalline deposits that develop within the macula) and thinning of the macula, reduces central vision and can effect color perception. In general, the damage caused by the "Dry" form is not as severe or rapid as that of the "Wet" form. However, over time Dry form of AMD can cause profound vision loss and no treatment available, but training and special devices can promote independence and a return to favourite activities. Thus, wet form AMD (CNV) reflects a pathologic angiogenic condition in which the loss of regulation over angiogenesis leads to the retinal damage.

\section{Angiogenic signaling}

Model studies using genetic and biochemical methods have facilitated in understanding the cellular mechanisms through which angiogenesis is regulated in both normal and pathological conditions. Stress inducing factors such as chronic hypoxia in the tumors, aging, ischemia, ultraviolet radiation and free radicals in Retinal Pigmented Epithelium (RPE), can lead to the upregulation, expression and secretion of excess angiogenic factors. Paracrine or autocrine angiogenic factors secreted in different tissues generally include Vascular Endothelial Growth Factors (VEGFs), Fibroblast Growth Factors (FGFs), angiopoietins (APs), transforming growth factors (TGFs), hepatocyte growth factor (HGF) etc. [7,11,12]. Angiogenic factors act as ligands and bind to their specific receptors on ECs among which the integrins and receptor tyrosinse kinases have gained significance as key regulators in angiogenic signaling [12]. Ligand bound receptors are activated through oligomerization through homodimer formation or binding to other receptors. The cytoplasmic domains of the activated receptors undergo modifications such as phosphorylation followed by recruitment of other downstream kinases which act as signaling modulators and inturn regulate gene expression patterns at transcriptional and translation levels [13-15]. Internalization of receptor bound angiogenic factors also leads to the activation of signaling modulators. The sequential signaling mechanism(s) lead to the activation of pathways that support survival of ECs under stress conditions, proliferation of ECs under stimulation by growth factors, release of different proteinases by ECs for remodeling of ECM, migration of ECs and finally organization into new capillaries [16,17]. Thus, angiogenesis is initiated and maintained through the regulation of signaling mechanisms in ECs and other cell types.

\section{Integrin mediated signaling in angiogenesis}

Integrins are transmembrane, heterodimeric proteins that act as receptors for various extracellular ligands, especially the components of ECM such as collagens, laminins, fibronectins, vitronectin, ECM bound growth factors and some proteases [18-20]. The heterodimers of integrins are composed of two subunit types' viz., $\alpha$ (18 isoforms) and $\beta$ (8 isoforms), of which different combinations are expressed in cellular specific manner. The extracellular domains of dimerized integrnis bind to different ECM ligands, whereas the intracellular and transmembrane domains transmit the signals to the intracellular kinases and other signal modulators [20]. The role of different integrins in regulation of angiogenesis has been deciphered by using integrin deficient cell and animal models, which revealed the significance of integrins in regulating the signaling corresponding to the survival, proliferation and migration of ECs [21]. Some of the signaling mechanisms mediated by different classes of integrins that are specifically inhibited by endogenous angioinhibitors are discussed in the following

\section{Transcription factors and angiogenesis}

Angiogenic signaling manifested as the cellular responses evident from morphological and migratory patterns of ECs, also involve the role of transcription factors that are either up regulated or stabilized during pathological angiogenesis. Hypoxia is one of the common condition that was identified in tumor microenvironment and ocular tissues, under stress, that leads to the stabilization of a key transcription factor viz., hypoxia inducible factor-1a (HIF-1 $\alpha$ ) which inturn upregulates expression of different genes that play role in angiogenesis such as Cyclooxygense-2 (COX-2), inducible nitric oxide synthase (iNOS), matrix metalloproteinases (MMPs) etc. [22-28]. Hypoxia also up-regulates the expression of angiogenic factors such as VEGF and enhances the hypoxic metabolism promoting the survival of ECs under stress conditions followed by proliferation and migration [22]. Nuclear factor kappa $B(N F-\kappa B)$ is another key transcriptional factor identified to play role in angiogenesis. Generation of reactive oxygen species (ROS) under stress conditions leads to the activation of kinase (K-ras) pathways that can activate NF- $\kappa B$ which inturn activates several genes such as chemokines that mediate angiogenesis $[22,29,30]$. In addition, several other transcription factors of basic helix-loop-helix, homeobox, E26 transforming specific family, zinc finger, nuclear hormone receptor families etc are also involved in angiogenesis [24].

\section{MMP's and angiogenesis}

Sprouting of new capillaries from the intact ones in angiogenesis involves not only the proliferation, but also migration of ECs into the angiogenic sites. The VBM or basal lamina forms a mechanical barrier to the ECs [26]. Therefore, degradation of VBM is a common process observed during angiogenesis which facilitates the invasion of ECs, removal of ECM components that obstruct invasion or migration, release of sequestered growth factors and also provision of space for new capillary growth [26]. These functions of ECM or basal lamina degradation are carried out by the proteases, MMPs that are present either on the cell surface, released into extracellular milieu or some of those present within the cell. The expression of the MMPs is low in quiescent ECs and up-regulated in the sprouting ECs through the signaling mechanisms elicited by the hypoxia and secreted proangiogenic factors [31]. In addition, regulation of MMP activity is also achieved through their inhibitors that are present within the tissues. 
Citation: Gunda V, Sudhakar YA (2013) Regulation of Tumor Angiogenesis and Choroidal Neovascularization by Endogenous Angioinhibitors. J Cancer Sci Ther 5: 417-426. doi:10.4172/1948-5956.1000417

MMPs are endopeptidases, which require zinc for their activities [32]. Different secreted and membrane bound MMPs (23 types in human) have been identified with distinct substrate specificities $[26,31,33]$. In particular MMP-2, MMP-9 and membrane bound MT1MMP are identified to be involved in angiogenesis. Gene deletion studies in mice have ascertained the role of these three MMPs in the initiation of tumor and physiological angiogenesis [34,35]. The role of MMP-2, MMP-9, MT1-MMP etc., has also been studied in the progression of CNV in ocular tissues [36,37]. MMPs can act as gelatinases and elastases that degrade the ECM components, release the inactive growth factors and also release the membrane receptor fragments such as of Notch, which plays pivotal role in capillary and tip cell differentiation in angiogenesis [38,39]. Some of the MMPs are also shown to exhibit anti-angiogenic properties.

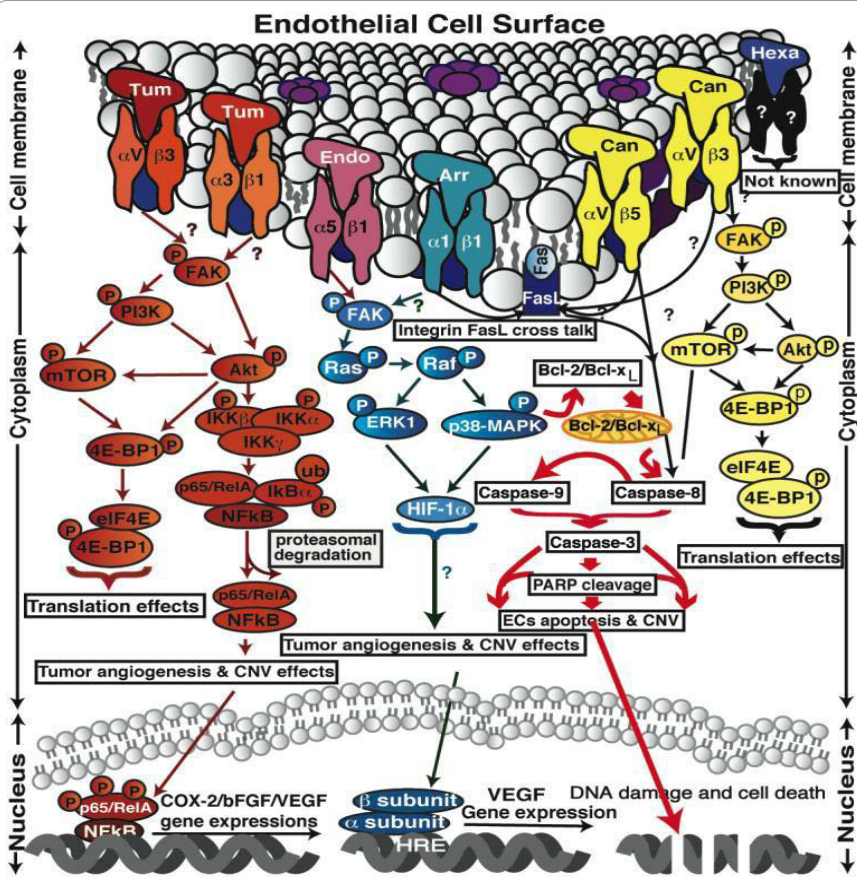

Figure 1: Schematic illustration of ECM derived endogenous angioinhibitors' signaling. Tumstatin, endostatin, arresten and canstatin interact with $\alpha \vee \beta 3 / \alpha 3 \beta 1, \alpha 5 \beta 1, \alpha 1 \beta 1$ and $\alpha V \beta 3 / \alpha V \beta 5$ integrins respectively, to inhibit the phosphorylation of focal adhesion kinase (FAK). Tumstatin: It binds to $\alpha V \beta 3$ and $\alpha 3 \beta 1$ integrins and inhibits phosphorylation of FAK, PI3-K Akt, mTOR, elF4E and 4E-BP1 to decrease endothelial cell protein synthesis and proliferation. In addition tumstatin also inhibits NF B mediated signaling in hypoxic conditions leading to the inhibition of COX-2, VEGF and bFGF expressions, resulting in inhibition of hypoxic tumor angiogenesis and LASER induced CNV. Endostatin: It binds to $\alpha 5 \beta 1$ integrin and inhibits phosphorylation of FAK, causes inhibition of Ras, Raf, extra cellular signal related kinase-1 (ERK1) and p38 MAPK pathways that leads to inhibition of endothelial cell migration and tube formation and promotes apoptosis in LASER induced CNV. Arresten: It binds to $\alpha 1 \beta 1$ integrin and inhibits phosphorylation of FAK, causes inhibition of Ras, Raf, ERK1 and p38 MAPK pathways that leads to inhibition of HIF-1a addition arresten initiates two apoptotic pathways, involving activation of caspase- 9 and -8 , leading to activation of caspase- 3 and PARP cleavage. (a) Arresten activates caspase-3 directly through inhibition of FAK/p38-MAPK/ $\mathrm{Bcl}-2 / \mathrm{Bcl}-\mathrm{xL}$ and activation of caspase-9; (b) Integrin a1b1 cross talk with Fas-L through mitochondrial pathway and leads to activation of caspase- 8 and-3 in proliferating endothelial cells. Canstatin: It binds to $\alpha V \beta 3 / \alpha V \beta 5$ integrins and inhibits two apoptotic pathways, involving activation of caspase- 8 and casoase-9, leading to activation of caspase-3. Canstatin activates procaspase- 9 not only through inhibition of the FAK/PI3K/AKT pathways but also by integrins cross talking mitochondrial pathway through Fas- $L$ dependent caspase- 8 activation leads to endothelial cell apoptosis in LASER induced CNV models. $\mathrm{CM}$ represents cell membrane. Hexastatin: Its receptor and mediated signaling is not yet known.

\section{Regulation of pathological angiogenesis by endogenous angioinhibitors}

In addition to the angiogenic factors which activate angiogenesis, tissues and especially ECM possess endogenous angioinhibitors, which include the fragments or molecules derived from macromolecules or metabolites produced within the body and identified with the potency to halt angiogenic process [40]. They are either sequestered into ECM or secreted as soluble molecules and regulate angiogenesis by inhibiting the survival, proliferation and migration of activated ECs and degradation of VBM. There are about more than 40 endogenous inhibitors being characterized and those derived from proteinaceous components of ECM or secreted by degradation of VBM are widely studied for their abundance and occurrence in the VBM of capillaries. Endogenous angioinhibitors are also secreted into vasculature and thus organized vasculature in healthy tissues is maintained by the balanced action of angiogenic factors and angioinhibitors [40-42]. However, in pathological angiogenesis, angiogenic factors are secreted in higher levels compared to angioinhibitors, thus leading to an imbalance between the angiogenic factors and angioinhibitors causing aberrant vascular growth as evident in tumor vascularization and CNV. Therefore, studies to evaluate the search for angioinhibitors with potential to inhibit uncontrolled angiogenesis and in depth studies pertaining to the mechanisms of pathological angiogenesis regulation are in progress.

\section{Extra cellular matrix derived endogenous angioinhibitors}

Vascular Basement Membrane (VBM) provides support to the endothelium maintaining the integrity and functioning of capillaries. VBM also supports angiogenesis by regulating the migration, proliferation and survival of ECs, acting as guiding scaffold during lumen formation and maturation of capillaries [43]. These effects are mediated partly by the interaction of the cells with the Extra Cellular Matrix (ECM) components. ECM also sequesters the growth factors, which are released into pericellular milieu by the degradation of ECM during angiogenesis $[40,44]$. However, it is also known that degradation of VBM also leads to release of fragments of ECM components, which act as endogenous angioinhibitors.

\section{Collagen derivatives}

Collagens are the abundant components of ECM constituting scaffold and basement membrane constituents of different body tissues [12]. They form the major structural and functional constituents of the VBM. Around 13 different types of collagens are known to constitute the VBM in vascular tissues and small peptides derived from type IV, XVII and XV collagens have been shown to act as endogenous angioinhibitors.

Arresten: Arresten [ $\alpha 1(\mathrm{IV}) \mathrm{NC1}$ ] is the $26-\mathrm{kDa}$ collagen type IV, al chain derived non-collagenous (NC1) domain which functions via binding to a1 $\beta 1$ integrin and heparan sulfate proteolgycans regulating bFGF and VEGF stimulated activation of ECs. It inhibits the survival of mouse lung endothelial cells through inhibition of FAK phopshorylation in AKT independent manner [14,45,46]. FAK inhibition by $\alpha 1(\mathrm{IV}) \mathrm{NC} 1$ via $\alpha 1 \beta 1$ integrin leads to downstream inhibition of Raf/MEK/ERK1/2/p38 MAPK and HIF-1a [14] Inhibition of HIF-1 $1 \alpha$ by arresten is critical in preventing hypoxic survival of ECs through VEGF regulation. Arresten also affects the metastasis leading to reduction of renal carcinomas in-vivo [14]. In addition to anti-tumoral properties, antiangiogenic activity of arresten 
Citation: Gunda V, Sudhakar YA (2013) Regulation of Tumor Angiogenesis and Choroidal Neovascularization by Endogenous Angioinhibitors. J Cancer Sci Ther 5: 417-426. doi:10.4172/1948-5956.1000417

was also found to inhibit bFGF-induced proliferation of mouse retinal endothelial cells (MREC), in-vitro in a dose dependent manner. It inhibited the bFGF-induced migration of MREC mediated by MMP-2, activity but not the expression levels of MMP-2 [47]. In-vivo studies have also shown that LASER induced Choroidal Neovascularisation (CNV) is inhibited by arresten in mice models. Thus, arresten has been shown to effect the proliferation and migration of endothelial cells, regulation of tumors and $\mathrm{CNV}$ in both tumor and retinal angiogenesis (author's unpublished findings).

Canstatin: It is the $24-\mathrm{kDa}$ collagen type IV, $\alpha 2$ derived noncollagenous (NC1) domain [ $\alpha 2(\mathrm{IV}) \mathrm{NC1}$, which binds to the $\alpha \mathrm{V} \beta 3$ and $\alpha \mathrm{V} \beta 5$ integrins inhibiting EC proliferation, tube formation and migration by enhancing apoptosis in these cells [48-51]. The angioinhibitory signaling mechanism(s) of canstatin have been identified using different in-vitro and in-vivo models [52,53]. Cantstain was shown to induce apoptosis through the induction of Fas-ligand, activation of procaspse- 8 and -9 cleavage, reduction in membrane potential, inhibition of Akt, FAK, mToR, eIF-4EBP-1 and ribosomal S6-kinase phosphorylations, in cultured ECs [54]. The caspase-9 mediated apoptotic activation in both endothelial and tumor cells by recombinant canstatin (recombinant adenovirus AdCanHSA) were mediated through the cross talk between $\alpha \mathrm{V} \beta 3$ and $\alpha \mathrm{V} \beta 5$ integrin receptors [48]. Recombinant CanHSA was also reported to sensitize the tumors to radiotherapy by modulating the HIF-1a induced apoptosis of tumor cells [49]. Canstatin also suppressed growth of large and small size tumors in two human xenograft mouse models in-vivo [51]. The antiangiogenic efficacy of canstatin was further confirmed by inhibition of in-vivo LASER induced choroidal neovasculasisation and in alkali burn induced corneal neovascularization in different mice models $[55,56]$.

Tumstatin: Tumstatin [ $\alpha 3(\mathrm{IV}) \mathrm{NC} 1]$ is a $28-\mathrm{kDa}$ collagen type IV, $\alpha 3$ chain derived non-collagenous ( $\mathrm{NC1}$ ) domain with angioinhibitory and proapoptotic activities. It binds to the CD47/IAP, $\alpha \mathrm{V} \beta 3, \alpha 3 \beta 1$ and $\alpha 6 \beta 1$ integrin(s) and inhibits the signaling cascade mediated by FAK, Akt, PI3K/mTOR/eIF-4E/4EBP1 and NFkB/COX-2 [15,22,57-60]. Inhibition of eIF-4E/4EBP1 by tumstatin leads to the cap dependent translational level gene regulation, whereas inhibition of transcriptional factor signaling such as NFKB leads to regulation of genes such as COX-2 at the transcriptional level. Thus tumstatin exhibits gene regulation in endothelail cell-specific and integrin dependent manner [22]. Tumstatin, or its derivative peptides and tumstatin gene delivery have been shown to exhibit anti-tumor properties both in-vitro and in-vivo, when applied individually or in combination drug studies [61]. Several studies have ascertained angioinhibitory and antitumor properties of tumstatin using in-vitro melanoma, hepatoma cell lines etc., and in-vivo in gastric/colon carcinomas and ovarian cancers [62-65]. Tumstatin is generally found in the circulation and mice with a genetic deletion of Col(IV)a3 show abnormal tumor growth together with enhanced pathological angiogenesis; whereas physiological angiogenesis associated with development, wound healing and liver regeneration were unaltered [57]. Supplementing Col(IV)a3-deficient mice with normal physiological concentration of recombinant tumstatin abolished the tumor growth rate confirming it as an endogenous angioinhibitor. The suppressive effects of tumstatin require integrins $\alpha \mathrm{V} \beta 3$ and $\alpha 3 \beta 1$ that are expressed on many pathological, but not on physiological angiogenic vasculature or blood

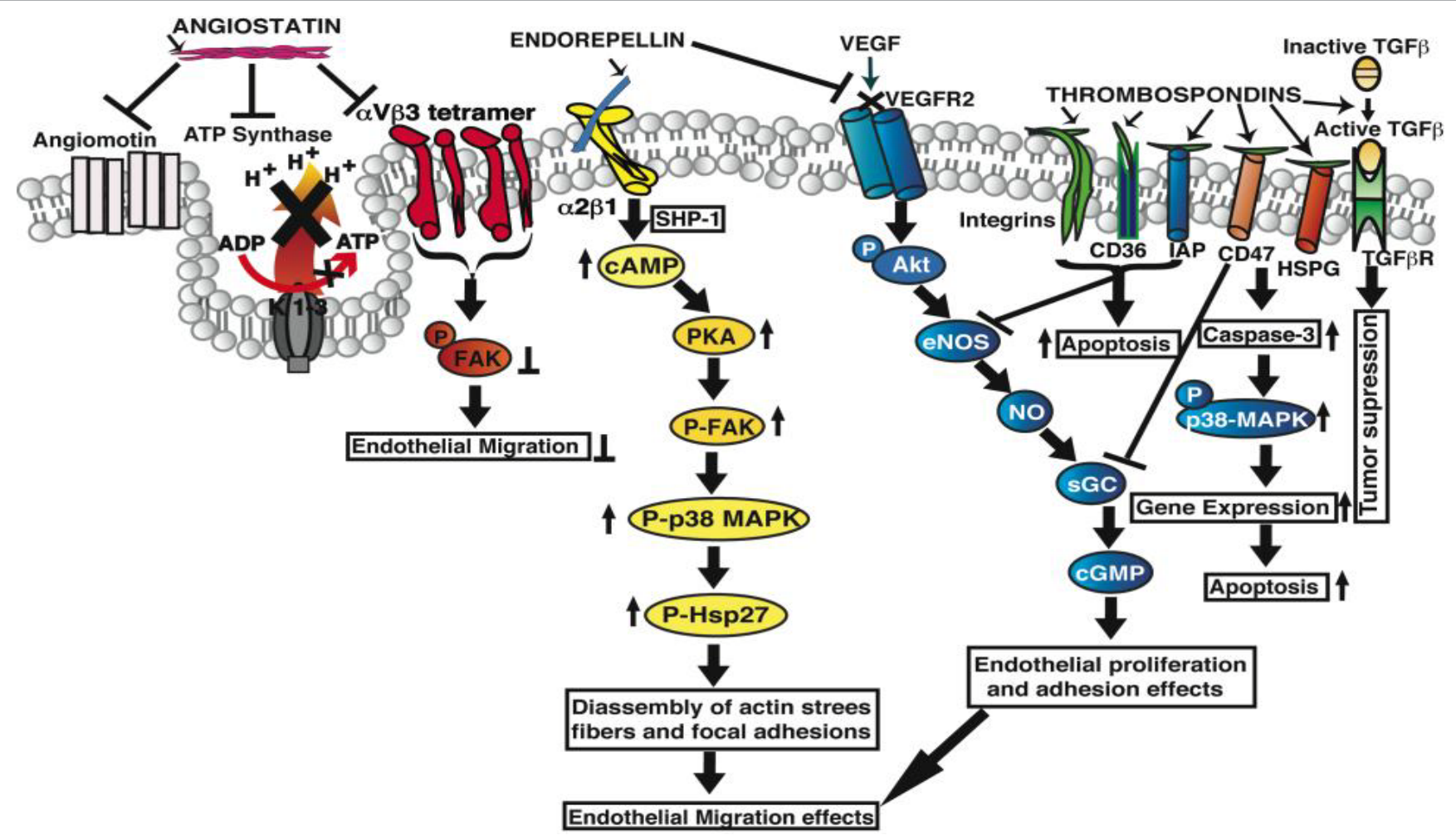

Figure 2: Schematic illustration of non-collagenous ECM derived endogenous angioinhibitors' signaling. Angiostatins: Bind ATP synthases, $\alpha V \beta 3$ integrin and angiomotin. Inhibit FAK activity by binding of integrins and ATP synthase of ECs. Endorepellin: Binds $\alpha 2 \beta 1$ integrins and VEGFR-2. Binding to $\alpha 2 \beta 1$, TSP-1 activates cAMP-PKA/FAK/p38-MAPK/Hsp27. Thrombospondins (TSPs): Bind to CD36 and integrin associated protein (IAP) promoting Src-family protein kinases/Caspase-3/ p38 MAPK leading to apoptosis; different integrins ( $\alpha 3 \beta 1)$, CD47 and heparan sulfated proteoglycans (HSPGs) and TGF- $\beta$ promoting tumor cell death. 
vessels. The cleavage of Col(IV)a3 by matrix metallo proteinase- 9 (MMP-9) is known to lead to the physiological release of tumstatin, as lower concentrations of tumstatin were recorded in mice deficient in MMP-9 [58]. Administration of soluble recombinant tumstatin into mice also reduced the tumor growth and CD-31 positive endothelial vasculature in tumors. These studies indicate that tumstatin has endogenous function as $\alpha \mathrm{V} \beta 3 / \alpha 3 \beta 1$ integrins-dependent suppressor of pathological angiogenesis and tumor growth [59].

Hexastatin: Hexastatin, is the $25-\mathrm{kDa}$ carboxy terminal noncollagenous (NC1) domain of a chain of type (IV) collagen [a6(IV) NC1]. Recombinant human hexastatin was shown to inhibit EC proliferation and in-vivo neovascularization and the tumor growth in mouse models of cancer. Further, the peptides derived from hexastatin also exhibited the inhibition of proliferation and migration of HUVECs in-vitro [50,66]. Inhibition of elastin peptide-mediated angiogenic signaling inhibited in choroidal endothelial cells by hexastatin [67]. The signaling mechanisms elicited by the hexastatin and the putative integrins that can bind to this angioinhibitor are yet to be identified.

Tetrastatins and pentastatins: Bioinformatic studies have been applied to identify the endogenous angioinhibtory peptides, which facilitated the identification of tetra, penta and hexastatin peptides from the $\alpha \mathrm{IV}, \alpha \mathrm{V}$, and $\alpha \mathrm{VI}$ fibrils of type IV collagen respectively. The peptide derivatives were shown to exhibit angioinhibitory properties [68]. Pentastatin-1 is the 20-mer synthetic peptide, which inhibited migration and viability of HUVEC, NCI-H82-SCLC and 3T3 fibroblast cells, in vitro and also exhibited low toxicity in xenograft models [69]. $\beta 1$ and $\beta 3$ integrins are considered as the putative targets to which Pentastatin-1 binds and exhibits angioinhibitory activities [68].

Endostatin is the partial $20-\mathrm{kDa}$ fragment of collagen type XVIII, carboxy terminal, non collagenous domain ( $\mathrm{NC1}$ ), derived from the parent collagen by proteolytic cleavage activities of elastase and

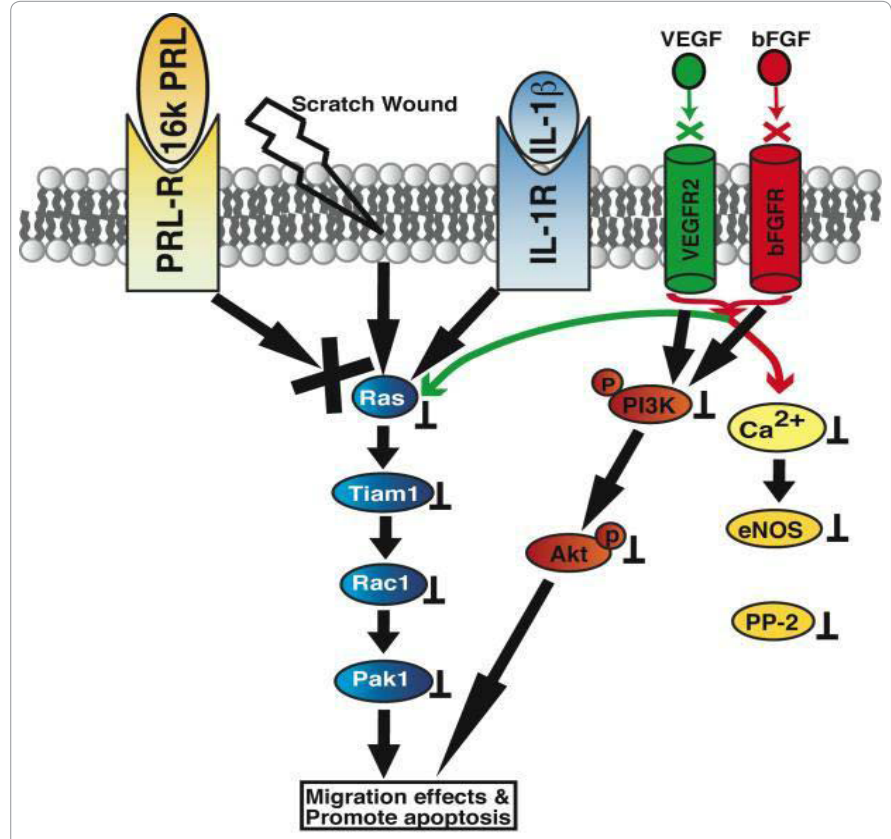

Figure 3: Schematic illustration of non-ECM derived endogenous angioinhibitor signaling. Vasoinhibins: Bind probably prolactin receptor (PLR) and IL-1 $\beta$. Inhibits Sos/Ras/MAPK, NOs/Raf/MAPK, and Ca2+/eNOs/ protein phosphatase 2 signaling. Promotes Ras/Tiam-1/Rac-1/Pak1 and $\mathrm{Bcl}-\mathrm{Xs}$ mediated apoptosis.
cathepsin-L [70]. It was initially identified in the conditioned media of hemangioendothelioma cell cultures, but later detected from various human tissues and sera in healthy and pathologic scenarios. Thus, endostatin is found in normal circulation enabling it to be utilized as an effective endogenous angioinhibitor without toxic effects. Endostatin elicits the anti-proliferative and anti-migratory effects by binding to different endothelial cell (ECs) surface molecules and regulating the signaling cascades [59]. Recombinant endostatin binds to aV integrins as shown in human endothelial cells [71]. Further studies have also shown localization of endostain in the lipid rafts and association with caveolae [72,73]. Surface plasmon resonance assays characterized the binding of endostatin to both $\alpha \mathrm{V} \beta 1$ integrin and the heparin sulfate proteoglycans and localization to the lipid rafts [71]. In-vitro assays using ECs also showed the colocalization of endostatin with a5 $\beta 1$ integrin, actin stress fibers and membrane anchor protein, caveolin-1 which enumerates the interaction of endostatin with caveolae, inhibiting EC migration through the disassembly of actin stress fibers/ focal adhesions, activation of Src and impaired fibronectin deposition by ECs in response to bFGF [59,73]. Binding of endostatin to another caveolae and eNOS linked heparin sulfate containing glycoprotein, called glypican, was also reported. Binding of endostatin with integrins down-regulates the activity of RhoA-GTPase and inhibits signaling pathways mediated by small kinases of the Ras and Raf families. In addition, binding to the KDR/Flk-1, endostatin inhibits the VEGFinduced tyrosine phosphorylation of KDR/Flk-1 and activation of ERK, p38 MAPK, and p125FAK in HUVECs [59,74]. Other signaling cascades regulated by the endostatin are also being identified which are mediated by activator protein 1 (Id), HIF1a, ephrin, tumor necrosis factor- $\alpha(\mathrm{TNF} \alpha)$, nuclear factor- $\kappa \mathrm{B}(\mathrm{NF} \kappa \mathrm{B})$, coagulation cascades, adhesion molecules and $\mathrm{Wnt}$, which indicate the potential role of endostatin as an endogenous angioinhibitor [75-77]. Due to such angioinhibitory potential, endostatin has been validated for regulation of pathological tumor and retinal angiogenesis in different studies. The clinical implications of effective tumor treatment with endostatin have been elaborated in other reviews. Lower levels of endotstain have been recorded in CNV samples compared with the healthy donor eyes and within the tissues of progressive AMD $[78,79]$. These observations along with the evidence of inhibition of CNV with intravenous injection of adenoviral vectors, that express secretable endostatin, corroborate the significance of endostatin in regulation of CNV.

\section{Non-collagenous derivatives}

Angiostatin: Angiostatins are $38-45 \mathrm{kDa}$ kringle domains derived from plasminogen by protease activity [80]. Though the parent molecule, plasminogen, has significant role in activation of fibrinogen and blood clotting, the derivative peptides exhibit angioinhibitory properties by inhibiting proliferation, migration and tube formation of proliferating ECs. Angiostatins bind to ATP synthases on the surface of ECs leading to their apoptotic death [81,82]. Further $\alpha \mathrm{V} \beta 3$ integrin and angiomotin are also shown to bind angiostatin $[81,82]$. The FAK activity is known to be disrupted by the binding of angiostatin to the integrins and ATP synthase of ECs in the hypoxic tumor microenvironment, thus leading to the death of ECs (Lawler, 2000). Regulation of the tumor growth and metastasis at clinical levels were proven possible with application of angiostatin and endostatin in different studies $[69,83,84]$. The application of angiostatin in regulating $\mathrm{CNV}$ of AMD was also evaluated by the expression of the peptides invivo, using adenoviral vectors [85].

Thrombospondins: Thrombospondins (TSPs) are secreted ECM 
Citation: Gunda V, Sudhakar YA (2013) Regulation of Tumor Angiogenesis and Choroidal Neovascularization by Endogenous Angioinhibitors. J Cancer Sci Ther 5: 417-426. doi:10.4172/1948-5956.1000417

\begin{tabular}{|c|c|c|c|c|}
\hline Angioinhibitor & Parent molecule & Targets & Receptors & Models of evaluation \\
\hline \multicolumn{5}{|c|}{ Collagenous derivatives } \\
\hline Arresten & collagen IV, $\alpha 1$ & $\alpha 1 \beta 1$ integrin, HSPG & Raf/MEK/ERK1/2/p38 MAPK HIF-1 $\alpha$ & In-vitro, Tumors studies \\
\hline Canstatin & collagen IV, $\alpha 2$ & $\begin{array}{l}\alpha \vee \beta 3, \alpha \bigvee \beta 5 \text { integrins } \\
\text { Fas }\end{array}$ & $\begin{array}{l}\text { procaspse-8 and -9 } \\
\text { Akt/FAK/mToR/elF-4EBP-1 } \\
\text { Ribosomal S6-kinase }\end{array}$ & $\begin{array}{l}\text { In-vitro, Tumors, alkali burn } \\
\text { CNV studies }\end{array}$ \\
\hline Tumstatin & collagen IV, a3 & $\mathrm{CD} 47 / \mathrm{IP}, \alpha \vee \beta 3, \alpha 6 \beta 1$ integrins & $\begin{array}{l}\text { FAK/Akt/PI3K/mT R/elF- } \\
\text { 4E/4EBP1/NFKB/C X-2 }\end{array}$ & In-vitro, Tumors studies \\
\hline Hexastatin & collagen IV, a6 & Not known & Not known & In-vitro, Tumors studies \\
\hline Endostatin & collagen XVIII & $\begin{array}{l}\alpha \bigvee \beta 1 / \alpha 5 \beta 1 \text { integrins } \mathrm{HSP}, \\
\text { Glypican caveolin-1 }\end{array}$ & $\begin{array}{l}\text { Ras/Raf/KDR/FIk-1/ERK/ } \\
\text { p38-MAPKVp125FAK/HIF1 } \\
\text { /Ephrin/TNF a/ NFKB /Wnt }\end{array}$ & $\begin{array}{l}\text { In-vitro, Tumors, CNV } \\
\text { studies }\end{array}$ \\
\hline Pentastatins and Tetrastatins & Collagen $a \mathrm{~V} \&$ alV & $\beta 1$ and $\beta 3$ integrins & Not known & In-vitro studies not known \\
\hline
\end{tabular}

Table 1: Collage Derived Angioinhibitors.

\begin{tabular}{|c|c|c|c|c|}
\hline Angioinhibitor & Parent molecule & Receptors & Targets & Models of evaluation \\
\hline \multicolumn{5}{|c|}{ Non-Collagenous derivatives } \\
\hline Angiostatin & Plasminogen & $\begin{array}{l}\text { ATP synthases, } \alpha \mathrm{V} \beta 3 \\
\text { integrin, angiomotin }\end{array}$ & Apoptotic pathway & $\begin{array}{l}\text { In-vitro Tumor and CNV } \\
\text { studies }\end{array}$ \\
\hline Thrombospondins & TSP & $\begin{array}{l}\text { CD36, IAP, CD } 47 \\
\text { HSPG, } \alpha 3 \beta 1, \text { other } \\
\text { integrins }\end{array}$ & $\begin{array}{l}\text { Src-family kinases/Caspase-3/ } \\
\text { p38 } \\
\text { MAPK, TGF- } \beta\end{array}$ & $\begin{array}{l}\text { In-vitro Tumor and CNV } \\
\text { studies }\end{array}$ \\
\hline Endorepellin & Perlecan & $\alpha 2 \beta 1$ integrins & $\begin{array}{l}\text { cAMP-PKA/FAK/p38-MAPK/ } \\
\text { Hsp27 } \\
\text { SHP-1, Ca2+ }\end{array}$ & In-vitro, Tumor studies \\
\hline Vasoinhibins & $\begin{array}{l}\text { Prolactin, growth hormone, } \\
\text { placental lactogen }\end{array}$ & Not known & $\begin{array}{l}\text { Sos/Ras/MAPK, eNOs/Raf/ } \\
\text { MAPK, } \\
\text { Ca2+/eNOs/protein phosphatase } \\
\text { 2, Ras/Tiam-1/Rac-1/Pak1, Bcl- } \\
\text { XL, NF-k } \beta\end{array}$ & In-vitro CNV studies \\
\hline PEDF & PEDF & Not known & Apoptosis & In-vivo CNV studies \\
\hline
\end{tabular}

Table 2: Non-Collage Derived Angioinhibitors.

glycoproteins playing key role in cellular and ECM interactions [86]. The N-terminal peptides derived from the TSPs, by the action of different proteases are identified to possess anti-globular domains with subunit molecular weight of $145-\mathrm{kDa}$ categorized under subgroup-A with anti-angiogenic properties and subgroup-B consists of TSP's 3-5 which are pentameric with subunit molecular weight of $110-\mathrm{kDa}$. TSP1 was the first naturally occurring inhibitor of angiogenesis identified, from the ECM of many normal tissues and produced by a variety of cells including platelets, megakaryocytes, epithelial, endothelial and stromal cells [87]. TSP-1 induces the apoptotic mechanism through CD36 and integrin associated protein (IAP)/Src-family protein kinases/Caspase-3/p38 MAPK [88]. In addition, TSP-1 can also bind to different integrins, CD47 and heparan sulfated proteoglycans [89]. Regulation of tumor angiogenesis and growth by TSP-1 are well documented in various studies. TGF- $\beta$ responsive tumor cells growth was shown to be suppressed through activation of TGF- $\beta$ mediated pathway by TSP-1 [90]. In addition VEGF stimulated EC migration was also inhibited through MMP inhibition by TSP-2 [91]. TSP-1 is also secreted by the retinal-pigmented epithelium (RPE) regulating angiogenisis in normal eye and lower levels of TSP-1 expression were identified with progression of AMD [78]. TSP-1 is however considered as an angiomodulator, since it was shown to inhibit retinal neovascularization in oxygen induced retinopathy, but stimulates angiogenesis by stimulating secretion of VEGF and FGF2 and it also promotes tumor cell survival and ECM interaction through $\alpha 3 \beta 1$ integrins [92].
Endorepellin: Perlecan is the large multifunctional heparin sulfate proteoglycan, found as a major component of ECM supporting angiogenesis [93]. However, the $80-\mathrm{kDa}, \mathrm{C}$-terminal derivative of perlecan, inhibits endothelial cell adhesion to fibronectin and type I collagen for which it was termed as "endorepellin" [94]. Endorepellin exhibits angioinhibitory activity by binding both $\alpha 2 \beta 1$ integrins and VEGFR-2 [94,95]. Recombinant and adenoviral expressed endorepellin inhibits migration and tube formation by binding to $\alpha 2 \beta 1$ integrins and activating signaling cascade including cAMP-PKA/FAK/p38MAPK/Hsp27 that leads to disassembly of actin and focal adhesions [94]. Regulation of endorepellin-elicited activity by Src homology-2 protein phosphatase-1 (SHP-1) was demonstrated in $\alpha 2 \beta 1^{-/-}$mice and siRNA models [96]. Dual receptor antagonism of endorepellin to both integrins and VEGFR-2 and SHP-1 modulation was also demonstrated in-vitro. Recently, the N-terminal laminin-like globular (LG3) domain of endorepellin, released by the activity of BMP-1/Tolloid family of metalloprotenases, was identified as the active angioinhibitory peptide and the levels of LG3 in the sera of many cancer patients were found to be lowered compared to normal subjects [97]. The in-vivo efficacy of endorepellin in controlling tumor growth was demonstrated using tumor xenograft models and endorepellin was found to localize in the periphery of tumors, enhancing hypoxia and thus preventing tumor survival [98].

\section{Non-ECM derived endogenous angioinhibitors}

Vasoinhibins: Vasoinhibins are naturally occurring angioinhibitory 
peptides found in the pituitary, retina and extrapituitary tissues derived from three different precursors, prolactin, growth hormone and placental lactogen, which do not exhibit angioinhibitory activities [99]. Vasoinhibins of molecular weights ranging from $14-18 \mathrm{kDa}$ were derived or expressed from the NH2-terminal regions of their precursors. Mechanisms of regulation of EC survival, proliferation and migration by the vasoinhibins have been deciphered in different studies; nevertheless, the receptors through which the mechanisms are mediated still remain enigmantic. Vasoinhibins regulate the EC migration and survival through inhibition of VEGF and bFGF stimulated MAPK activation [100]. VEGF activated Sos/Ras/MAPK or eNOs/Raf/MAPK proliferation signaling and $\mathrm{Ca} 2+/ \mathrm{eNO}$ /protein phosphatase 2 , mediated vascular permeability and vasodilation were shown to be inhibited by the vasoinhibins [101,102]. In addition vasoinhibins also inhibit migration of ECs stimulated by IL- $1 \beta$ through Ras/Tiam-1/Rac-1/Pak1 and promote apoptosis through conversion of Bcl-XL to proapoptoctic Bcl-Xs and NF- $\kappa \mathrm{B}$ mediated activation of initiator and effector caspases [103,104]. The therapeutic potential of vasoinhibins in regulating angiogenesis in $\mathrm{CNV}$ and tumor growth was evaluated and studies indicate that adenovirus mediated expression of vasoinhibins inhibit the LASER induced CNV in-vivo and angiogenesis in mice models [105]. However, the therapeutic potential of vasoinhibins in other retinopathic diseases is still controversial due to the speculated role of vasoinhibins in promoting progression of retinopathy of prematurity [106].

\section{Pigment epithelium derived factor (PEDF)}

Pigment Epithelium Derived Factor (PEDF) is a $50-\mathrm{kDa}$, secreted, serpin family glycoprotein, first identified from the cultured fetal RPE conditioned media. PEDF accumulates in the vitreous humor and is also expressed in different adult tissues. Addition of PEDF to the cultured HUVECs increased the number of TUNEL positive cells suggesting apoptotic mode of action of PEDF and thus possibly preventing EC response to ischemia in-vivo [107,108]. The level of PEDF found to be decreased in Bruch membrane with progression of AMD and a concomitant increase in VEGF levels was also identified with decrease in PEDF levels [78]. Different methods of PEDF upregulation have been applied to investigate the effect of PEDF on $\mathrm{CNV}$ in mice models. Intravitreous injections of adenovirus expressing the PEDF and ultrasound-microbubble technique of noninvasive gene transfer of PEDF gene in rats showed significant decrease in the CNV growth [109-111]. However, studies also demonstrated the lower levels of PEDF $(90 \mu \mathrm{g} / \mathrm{ml})$ has negative effect on CNV, whereas higher levels (2-4 fold) can augment CNV, thus indicating a strategic approach to be developed during clinical trials for CNV treatment with PEDF [112].

\section{Conclusions}

Role of angiogenesis in exaggerating the pathology of two of the leading pathological conditions viz., the tumor growth and the CNV of retina are well established. Regulation of aberrant angiogenesis in these two scenarios is warranted and endogenous angioinhibitors are considered as one of the optimal modalities for this purpose. The rationales for emphasis on usage of endogenous angioinhibitors lies in their origin from endogenous molecules and the occurrence of some of these angioinhibitors within the tissues, ECM or circulation in normal and pathological conditions. Regulation of integrin=, HSPG-, kinase-/secondary messenger-, NFkB-, Wnt-, mTOR-, eIF-4E/4EBP1-, COX-2- and MMP-mediated EC survival, proliferation and migration by these inhibitors, reflects the scope for angioinhibition at different stages of angiogenesis. Another issue of significance is the targeting by these inhibitors through different integrins, other receptors and the downstream signaling cascades that are found either only in abnormally proliferating ECs, but not in quiescent ECs, or upregulated in pathological hypoxic conditions. Studies so far indicate specificity of different endogenous angioinhibitors to their respective receptors and potential inhibition of angiogenic switches at the receptor, signaling mediator, transcriptional, translational and even at the ECM modulation levels. Also, the angiogenic signaling cascades regulated by them appear to be applicable for both the tumoral and CNV pathologic angiogenesis, as evident from some of the studies quoted above.

Further validation studies using strategies such as i) angioinhibitor combinations similar to endostain and angiostatin studied earlier, ii) combinations of different peptides derived from the angioinhibitors, iii) fusion molecules containing domains of different angioinhibitors and finally, iv) application of all known angioinhibitors for both tumoral angioinhibtion and $\mathrm{CNV}$ would be essential for successful clinical application and treatment of the angiogenic supported pathologies by the endogenous angioinhibitors.

\section{Acknowledgements}

This study was supported by Flight Attendant Medical Research Institute Young Clinical Scientist Award Grant FAMRI-062558, NIH/NCI Grant RO1CA143128, to YS.

\section{References}

1. Hoeben A, Landuyt B, Highley MS, Wildiers H, Van Oosterom AT, et al. (2004) Vascular endothelial growth factor and angiogenesis. Pharmacol Rev 56: 549580 .

2. Bergers G, Song S (2005) The role of pericytes in blood-vessel formation and maintenance. Neuro Oncol 7: 452-464.

3. Nakatsu MN, Sainson RC, Aoto JN, Taylor KL, Aitkenhead M, et al. (2003) Angiogenic sprouting and capillary lumen formation modeled by human umbilical vein endothelial cells (HUVEC) in fibrin gels: the role of fibroblasts and Angiopoietin-1. Microvasc Res 66: 102-112.

4. Asahara T, Kawamoto A (2004) Endothelial progenitor cells for postnatal vasculogenesis. Am J Physiol Cell Physiol 287: C572-579.

5. Folkman J (1971) Tumor angiogenesis: therapeutic implications. N Engl J Med 285: $1182-1186$

6. Jain RK (2005) Normalization of tumor vasculature: an emerging concept in antiangiogenic therapy. Science 307: 58-62.

7. Alon T, Hemo I, Itin A, Pe'er J, Stone J, et al. (1995) Vascular endothelia growth factor acts as a survival factor for newly formed retinal vessels and has implications for retinopathy of prematurity. Nat Med 1: 1024-1028.

8. Grossniklaus HE, Ling JX, Wallace TM, Dithmar S, Lawson DH, et al. (2002) Macrophage and retinal pigment epithelium expression of angiogenic cytokines in choroidal neovascularization. Mol Vis 8: 119-126.

9. Dvorak HF, Brown LF, Detmar M, Dvorak AM (1995) Vascular permeability factor/vascular endothelial growth factor, microvascular hyperpermeability, and angiogenesis. Am J Pathol 146: 1029-1039.

10. Roberts WG, Palade GE (1995) Increased microvascular permeability and endothelial fenestration induced by vascular endothelial growth factor. $\mathrm{J}$ Cell Sci 108 : 2369-2379.

11. Lu M, Adamis AP (2006) Molecular biology of choroidal neovascularization Ophthalmol Clin North Am 19: 323-334.

12. Sudhakar A, Kalluri R (2010) Molecular mechanisms of angiostatis. Encyclopedia of the eye 3 M-P: 52-59.

13. Siemerink MJ, Augustin AJ, Schlingemann RO (2010) Mechanisms of ocular angiogenesis and its molecular mediators. Dev Ophthalmol 46: 4-20.

14. Sudhakar A, Nyberg P, Keshamouni VG, Mannam AP, Li J, et al. (2005) Human alpha1 type IV collagen NC1 domain exhibits distinct antiangiogenic activity mediated by alpha1beta1 integrin. J Clin Invest 115: 2801-2810. 
Citation: Gunda V, Sudhakar YA (2013) Regulation of Tumor Angiogenesis and Choroidal Neovascularization by Endogenous Angioinhibitors. J Cancer Sci Ther 5: 417-426. doi:10.4172/1948-5956.1000417

15. Maeshima Y, Sudhakar A, Lively JC, Ueki K, Kharbanda S, et al. (2002) Tumstatin, an endothelial cell-specific inhibitor of protein synthesis. Science 295: 140-143.

16. Carmeliet P, Jain RK (2000) Angiogenesis in cancer and other diseases. Nature 407: 249-257

17. Kalluri R (2003) Basement membranes: structure, assembly and role in tumour angiogenesis. Nat Rev Cancer 3: 422-433.

18. Humphries JD, Byron A, Humphries MJ (2006) Integrin ligands at a glance. $J$ Cell Sci 119: 3901-3903.

19. Stupack DG, Cheresh DA (2002) Get a ligand, get a life: integrins, signaling and cell survival. J Cell Sci 115: 3729-3738.

20. Stupack DG, Cheresh DA (2002) ECM remodeling regulates angiogenesis: endothelial integrins look for new ligands. Sci STKE 2002: pe7.

21. Cheresh DA, Stupack DG (2002) Integrin-mediated death: an explanation of the integrin-knockout phenotype? Nat Med 8: 193-194.

22. Boosani CS, Mannam AP, Cosgrove D, Silva R, Hodivala-Dilke KM, et al. (2007) Regulation of COX-2 mediated signaling by alpha3 type IV noncollagenous domain in tumor angiogenesis. Blood 110: 1168-1177.

23. Qazi Y, Maddula S, Ambati BK (2009) Mediators of ocular angiogenesis. J Genet 88: 495-515

24. Sato $Y(2000)$ Molecular mechanism of angiogenesis transcription factors and their therapeutic relevance. Pharmacol Ther 87: 51-60.

25. Avraamides CJ, Garmy-Susini B, Varner JA (2008) Integrins in angiogenesis and lymphangiogenesis. Nat Rev Cancer 8: 604-617.

26. Egeblad M, Werb Z (2002) New functions for the matrix metalloproteinases in cancer progression. Nat Rev Cancer 2: 161-174.

27. Oklu R, Walker TG, Wicky S, Hesketh R (2010) Angiogenesis and current antiangiogenic strategies for the treatment of cancer. J Vasc Interv Radiol 21 $1791-1805$.

28. Mettouchi A, Meneguzzi G (2006) Distinct roles of beta1 integrins during angiogenesis. Eur J Cell Biol 85: 243-247.

29. Li M, Wu ZM, Yang $H$, Huang SJ (2011) NFî̄o B and JNK/MAPK activation mediates the production of major macrophage- or dendritic cell-recruiting chemokine in human first trimester decidual cells in response to proinflammatory stimuli. J Clin Endocrinol Metab 96: 2502-2511.

30. Aurora AB, Biyashev D, Mirochnik Y, Zaichuk TA, Sánchez-Martinez C, et al. (2010) NF-kappaB balances vascular regression and angiogenesis via chromatin remodeling and NFAT displacement. Blood 116: 475-484.

31. Page-McCaw A, Ewald AJ, Werb Z (2007) Matrix metalloproteinases and the regulation of tissue remodelling. Nat Rev Mol Cell Biol 8: 221-233.

32. van Hinsbergh VW, Koolwijk P (2008) Endothelial sprouting and angiogenesis: matrix metalloproteinases in the lead. Cardiovasc Res 78: 203-212.

33. Newby AC (2005) Dual role of matrix metalloproteinases (matrixins) in intimal thickening and atherosclerotic plaque rupture. Physiol Rev 85: 1-31.

34. Pozzi A, LeVine WF, Gardner HA (2002) Low plasma levels of matrix metalloproteinase 9 permit increased tumor angiogenesis. Oncogene 21: 272 281.

35. Deryugina El, Quigley JP (2006) Matrix metalloproteinases and tumor metastasis. Cancer Metastasis Rev 25: 9-34.

36. Chau KY, Sivaprasad S, Patel N, Donaldson TA, Luthert PJ, et al. (2008) Plasma levels of matrix metalloproteinase-2 and -9 (MMP-2 and MMP-9) in age-related macular degeneration. Eye (Lond) 22: 855-859.

37. Alge-Priglinger CS, Kreutzer T, Obholzer K, Wolf A, Mempel M, et al. (2009) Oxidative stress-mediated induction of MMP-1 and MMP-3 in human RPE cells. Invest Ophthalmol Vis Sci 50: 5495-5503.

38. Marron MB, Singh H, Tahir TA, Kavumkal J, Kim HZ, et al. (2007) Regulated proteolytic processing of Tie1 modulates ligand responsiveness of the receptortyrosine kinase Tie2. J Biol Chem 282: 30509-30517.

39. Gridley T (2007) Notch signaling in vascular development and physiology. Development 134: 2709-2718.
40. Nyberg P, Xie L, Kalluri R (2005) Endogenous inhibitors of angiogenesis Cancer Res 65: 3967-3979.

41. Folkman J (2007) Angiogenesis: an organizing principle for drug discovery? Nat Rev Drug Discov 6: 273-286.

42. Folkman $\mathrm{J}$ (2007) Is angiogenesis an organizing principle in biology and medicine? J Pediatr Surg 42: 1-11.

43. Davis GE, Senger DR (2005) Endothelial extracellular matrix: biosynthesis, remodeling, and functions during vascular morphogenesis and neovessel stabilization. Circ Res 97: 1093-1107.

44. Clamp AR, Jayson GC (2005) The clinical potential of antiangiogenic fragments of extracellular matrix proteins. Br J Cancer 93: 967-972.

45. Colorado PC, Torre A, Kamphaus G, Maeshima Y, Hopfer H, et al. (2000) Antiangiogenic cues from vascular basement membrane collagen. Cancer Res 60 : 2520-2526.

46. Nyberg P, Xie L, Sugimoto H, Colorado P, Sund M, et al. (2008) Characterization of the anti-angiogenic properties of arresten, an alpha1beta1 integrindependent collagen-derived tumor suppressor. Exp Cell Res 314: 3292-3305.

47. Boosani CS, Nalabothula N, Sheibani N, Sudhakar A (2010) Inhibitory effects of arresten on bFGF-induced proliferation, migration, and matrix metalloproteinase-2 activation in mouse retinal endothelial cells. Curr Eye Res 35: 45-55.

48. Magnon C, Galaup A, Mullan B, Rouffiac V, Bouquet C, et al. (2005) Canstatin acts on endothelial and tumor cells via mitochondrial damage initiated through interaction with alphavbeta3 and alphavbeta5 integrins. Cancer Res 65: 43534361.

49. Magnon C, Opolon P, Ricard M, Connault E, Ardouin P, et al. (2007) Radiation and inhibition of angiogenesis by canstatin synergize to induce HIF-1alphamediated tumor apoptotic switch. J Clin Invest 117: 1844-1855.

50. Petitclerc E, Boutaud A, Prestayko A, Xu J, Sado Y, et al. (2000) New functions for non-collagenous domains of human collagen type IV. Novel integrin ligands inhibiting angiogenesis and tumor growth in vivo. J Biol Chem 275: 8051-8061.

51. Kamphaus GD, Colorado PC, Panka DJ, Hopfer H, Ramchandran R, et al (2000) Canstatin, a novel matrix-derived inhibitor of angiogenesis and tumor growth. J Biol Chem 275: 1209-1215.

52. Magnon C, Opolon P, Connault E, Mir LM, Perricaudet M, et al. (2008) Canstatin gene electrotransfer combined with radiotherapy: preclinical trials for cancer treatment. Gene Ther 15: 1436-1445.

53. Narazaki M, Tosato G (2006) Canstatin: an inhibitor of angiogenesis and tumor growth revisited. Cancer J 12: 110-112.

54. Panka DJ, Mier JW (2003) Canstatin inhibits Akt activation and induces Fasdependent apoptosis in endothelial cells. J Biol Chem 278: 37632-37636.

55. Lima E Silva R, Kachi S, Akiyama H, Shen J, Aslam S, et al. (2006) Recombinant non-collagenous domain of alpha2(IV) collagen causes involution of choroidal neovascularization by inducing apoptosis. J Cell Physiol 208: 161-166.

56. Wang $Y$, Yin H, Chen $P$, Xie L, Wang Y (2011) Inhibitory effect of canstatin in alkali burn-induced corneal neovascularization. Ophthalmic Res 46: 66-72.

57. Hamano $Y$, Zeisberg M, Sugimoto H, Lively JC, Maeshima Y, et al. (2003) Physiological levels of tumstatin, a fragment of collagen IV alpha3 chain, are generated by MMP-9 proteolysis and suppress angiogenesis via alphaV beta3 integrin. Cancer Cell 3: 589-601.

58. Monboisse JC, Garnotel R, Bellon G, Ohno N, Perreau C, et al. (1994) The alpha 3 chain of type IV collagen prevents activation of human polymorphonuclear leukocytes. J Biol Chem 269: 25475-25482.

59. Sudhakar A, Sugimoto H, Yang C, Lively J, Zeisberg M, et al. (2003) Human tumstatin and human endostatin exhibit distinct antiangiogenic activities mediated by alpha vbeta 3 and alpha 5beta 1 integrins. Proc Natl Acad Sci U S A 100: 4766-4771.

60. Maeshima Y, Colorado PC, Torre A, Holthaus KA, Grunkemeyer JA, et al (2000) Distinct antitumor properties of a type IV collagen domain derived from basement membrane. J Biol Chem 275: 21340-21348.

61. Maeshima Y, Yerramalla UL, Dhanabal M, Holthaus KA, Barbashov S, et al. (2001) Extracellular matrix-derived peptide binds to alpha(v)beta(3) integrin and inhibits angiogenesis. J Biol Chem 276: 31959-31968. 
Citation: Gunda V, Sudhakar YA (2013) Regulation of Tumor Angiogenesis and Choroidal Neovascularization by Endogenous Angioinhibitors. J Cancer Sci Ther 5: 417-426. doi:10.4172/1948-5956.1000417

62. Goto T, Ishikawa H, Matsumoto K, Nishimura D, Kusaba M, et al. (2008) Tum-1, a tumstatin fragment, gene delivery into hepatocellular carcinoma suppresses tumor growth through inhibiting angiogenesis. Int J Oncol 33: 33-40.

63. Chung IS, Son YI, Ko YJ, Baek CH, Cho JK, et al. (2008) Peritumor injections of purified tumstatin delay tumor growth and lymphatic metastasis in an orthotopic oral squamous cell carcinoma model. Oral Oncol 44: 1118-1126.

64. Pasco S, Brassart B, Ramont L, Maquart FX, Monboisse JC (2005) Control of melanoma cell invasion by type IV collagen. Cancer Detect Prev 29: 260-266.

65. Zhang GM, Sui LH, Jia T, Zhao YZ, Fu SB, et al. (2008) [Inhibitory effect of recombinant anti-angiogenic peptide of tumstatin on growth and metastasis of human ovarian cancer transplanted in nude mice]. Zhonghua Zhong Liu Za Zh 30: $170-173$

66. Mundel TM, Yliniemi AM, Maeshima Y, Sugimoto H, Kieran M, et al. (2008) Type IV collagen alpha6 chain-derived noncollagenous domain 1 (alpha6(IV) NC1) inhibits angiogenesis and tumor growth. Int J Cancer 122: 1738-1744.

67. Gunda V, Verma RK, Sudhakar AY (2013) Inhibition of Elastin PeptideMediated Angiogenic Signaling Mechanism(s) in Choroidal Endothelial Cells by the a6(IV)NC1 Collagen Fragment. Invest Ophthalmol Vis Sci (Publication ahead of print: accepted).

68. Karagiannis ED, Popel AS (2007) Identification of novel short peptides derived from the alpha 4, alpha 5, and alpha 6 fibrils of type IV collagen with antiangiogenic properties. Biochem Biophys Res Commun 354: 434-439.

69. Koskimaki JE, Karagiannis ED, Tang BC, Hammers H, Watkins DN, et al. (2010) Pentastatin-1, a collagen IV derived 20-mer peptide, suppresses tumor growth in a small cell lung cancer xenograft model. BMC Cancer 10: 29.

70. Felbor U, Dreier L, Bryant RA, Ploegh HL, Olsen BR, et al. (2000) Secreted cathepsin $L$ generates endostatin from collagen XVIII. EMBO J 19: 1187-1194.

71. Ricard-Blum S, Féraud O, Lortat-Jacob H, Rencurosi A, Fukai N, et al. (2004) Characterization of endostatin binding to heparin and heparan sulfate by surface plasmon resonance and molecular modeling: role of divalent cations. J Biol Chem 279: 2927-2936.

72. Wickström SA, Alitalo K, Keski-Oja J (2002) Endostatin associates with integrin alpha5beta1 and caveolin-1, and activates Src via a tyrosyl phosphatasedependent pathway in human endothelial cells. Cancer Res 62: 5580-5589.

73. Wickström SA, Alitalo K, Keski-Oja J (2003) Endostatin associates with lipid rafts and induces reorganization of the actin cytoskeleton via down-regulation of RhoA activity. J Biol Chem 278: 37895-37901.

74. Ling Y, Yang Y, Lu N, You QD, Wang S, et al. (2007) Endostar, a novel recombinant human endostatin, exerts antiangiogenic effect via blocking VEGF-induced tyrosine phosphorylation of KDR/FIk-1 of endothelial cells. Biochem Biophys Res Commun 361: 79-84.

75. Abdollahi A, Hahnfeldt P, Maercker C, Gröne HJ, Debus J, et al. (2004) Endostatin's antiangiogenic signaling network. Mol Cell 13: 649-663.

76. Hanai J, Gloy J, Karumanchi SA, Kale S, Tang J, et al. (2002) Endostatin is a potential inhibitor of Wnt signaling. J Cell Biol 158: 529-539.

77. Hanai J, Dhanabal M, Karumanchi SA, Albanese C, Waterman M, et al. (2002) Endostatin causes G1 arrest of endothelial cells through inhibition of cyclin D1. J Biol Chem 277: 16464-16469.

78. Bhutto IA, Uno K, Merges C, Zhang L, McLeod DS, et al. (2008) Reduction of endogenous angiogenesis inhibitors in Bruch's membrane of the submacular region in eyes with age-related macular degeneration. Arch Ophthalmol 126: $670-678$

79. Fukai N, Eklund L, Marneros AG, Oh SP, Keene DR, et al. (2002) Lack of collagen XVIII/endostatin results in eye abnormalities. EMBO J 21: 1535-1544.

80. Hayashi M, Tamura Y, Dohmae N, Kojima S, Shimonaka M (2008) Plasminogen $\mathrm{N}$-terminal activation peptide modulates the activity of angiostatin-related peptides on endothelial cell proliferation and migration. Biochem Biophys Res Commun 369: 635-640.

81. Burwick NR, Wahl ML, Fang J, Zhong Z, Moser TL, et al. (2005) An Inhibitor of the F1 subunit of ATP synthase (IF1) modulates the activity of angiostatin on the endothelial cell surface. J Biol Chem 280: 1740-1745.

82. Tarui T, Miles LA, Takada $Y$ (2001) Specific interaction of angiostatin with integrin alpha(v)beta(3) in endothelial cells. J Biol Chem 276: 39562-39568.

83. Shantha Kumara HM, Tohme ST, Yan X, Nasar A, Senagore AJ, et al. (2011)
Plasma levels of angiostatin and endostatin remain unchanged for the first 3 weeks after colorectal cancer surgery. Surg Endosc 25: 1939-1944.

84. Tysome JR, Wang P, Alusi G, Briat A, Gangeswaran R, et al. (2011) Lister vaccine strain of vaccinia virus armed with the endostatin-angiostatin fusion gene: an oncolytic virus superior to dl1520 (ONYX-015) for human head and neck cancer. Hum Gene Ther 22: 1101-1108.

85. Lai CC, Wu WC, Chen SL, Xiao X, Tsai TC, et al. (2001) Suppression of choroidal neovascularization by adeno-associated virus vector expressing angiostatin. Invest Ophthalmol Vis Sci 42: 2401-2407.

86. Bornstein P (2001) Thrombospondins as matricellular modulators of cell function. J Clin Invest 107: 929-934.

87. Bornstein $P$ (2009) Thrombospondins function as regulators of angiogenesis. J Cell Commun Signal 3: 189-200.

88. Dawson DW, Pearce SF, Zhong R, Silverstein RL, Frazier WA, et al. (1997) CD36 mediates the In vitro inhibitory effects of thrombospondin-1 on endothelial cells. J Cell Biol 138: 707-717.

89. Kaur S, Kuznetsova SA, Pendrak ML, Sipes JM, Romeo MJ, et al. (2011) Heparan sulfate modification of the transmembrane receptor CD47 is necessary for inhibition of $\mathrm{T}$ cell receptor signaling by thrombospondin-1. J Biol Chem 286: 14991-15002.

90. Fitchev PP, Wcislak SM, Lee C, Bergh A, Brendler CB, et al. (2010) Thrombospondin-1 regulates the normal prostate in vivo through angiogenesis and TGF-beta activation. Lab Invest 90: 1078-1090.

91. Krady MM, Zeng J, Yu J, MacLauchlan S, Skokos EA, et al. (2008) Thrombospondin-2 modulates extracellular matrix remodeling during physiological angiogenesis. Am J Pathol 173: 879-891.

92. Lopez-Dee Z, Pidcock K, Gutierrez LS (2011) Thrombospondin-1: multiple paths to inflammation. Mediators Inflamm 2011: 296069.

93. Aviezer D, Hecht D, Safran M, Eisinger M, David G, et al. (1994) Perlecan basal lamina proteoglycan, promotes basic fibroblast growth factor-receptor binding, mitogenesis, and angiogenesis. Cell 79: 1005-1013.

94. Bix G, Fu J, Gonzalez EM, Macro L, Barker A, et al. (2004) Endorepellin causes endothelial cell disassembly of actin cytoskeleton and focal adhesions through alpha2beta1 integrin. J Cell Biol 166: 97-109.

95. Goyal A, Pal N, Concannon M, Paul M, Doran M, et al. (2011) Endorepellin the angiostatic module of perlecan, interacts with both the $\hat{I} \pm 2 \hat{I}^{2} 1$ integrin and vascular endothelial growth factor receptor 2 (VEGFR2): a dual receptor antagonism. J Biol Chem 286: 25947-25962.

96. Nyström A, Shaik ZP, Gullberg D, Krieg T, Eckes B, et al. (2009) Role of tyrosine phosphatase SHP-1 in the mechanism of endorepellin angiostatic activity. Blood 114: 4897-4906.

97. Gonzalez EM, Reed CC, Bix G, Fu J, Zhang Y, et al. (2005) BMP-1/Tolloid-like metalloproteases process endorepellin, the angiostatic C-terminal fragment of perlecan. J Biol Chem 280: 7080-7087.

98. Bix G, Castello R, Burrows M, Zoeller JJ, Weech M, et al. (2006) Endorepellin in vivo: targeting the tumor vasculature and retarding cancer growth and metabolism. J Natl Cancer Inst 98: 1634-1646.

99. Clapp C, Thebault S, Arnold E, García C, Rivera JC, et al. (2008) Vasoinhibins: novel inhibitors of ocular angiogenesis. Am J Physiol Endocrinol Metab 295: E772-778

100.D'Angelo G, Struman I, Martial J, Weiner RI (1995) Activation of mitogenactivated protein kinases by vascular endothelial growth factor and basic fibroblast growth factor in capillary endothelial cells is inhibited by the antiangiogenic factor $16-\mathrm{kDa} \mathrm{N}$-terminal fragment of prolactin. Proc Natl Acad Sci U S A 92: 6374-6378.

101. Gonzalez C, Corbacho AM, Eiserich JP, Garcia C, Lopez-Barrera F, et al. (2004) 16K-prolactin inhibits activation of endothelial nitric oxide synthase intracellular calcium mobilization, and endothelium-dependent vasorelaxation. Endocrinology 145: 5714-5722.

102.Ziche M, Morbidelli L (2000) Nitric oxide and angiogenesis. J Neurooncol 50 139-148.

103. Martini JF, Piot C, Humeau LM, Struman I, Martial JA, et al. (2000) The antiangiogenic factor $16 \mathrm{~K}$ PRL induces programmed cell death in endothelial cells by caspase activation. Mol Endocrinol 14: 1536-1549. 
Citation: Gunda V, Sudhakar YA (2013) Regulation of Tumor Angiogenesis and Choroidal Neovascularization by Endogenous Angioinhibitors. J Cancer Sci Ther 5: 417-426. doi:10.4172/1948-5956.1000417

104. Tabruyn SP, Sorlet CM, Rentier-Delrue F, Bours V, Weiner RI, et al. (2003) The antiangiogenic factor $16 \mathrm{~K}$ human prolactin induces caspase-dependent apoptosis by a mechanism that requires activation of nuclear factor-kappaB. Mol Endocrinol 17: 1815-1823.

105.Zhou SY, Xie ZL, Xiao O, Yang XR, Heng BC, et al. (2010) Inhibition of mouse alkali burn induced-corneal neovascularization by recombinant adenovirus encoding human vasohibin-1. Mol Vis 16: 1389-1398.

106. Clapp C, Aranda J, González C, Jeziorski MC, Martínez de la Escalera G (2006) Vasoinhibins: endogenous regulators of angiogenesis and vascular function. Trends Endocrinol Metab 17: 301-307.

107. Tombran-Tink J, Chader GG, Johnson LV (1991) PEDF: a pigment epitheliumderived factor with potent neuronal differentiative activity. Exp Eye Res 53: 411-414.

108. Ho TC, Chen SL, Yang YC, Liao CL, Cheng HC, et al. (2007) PEDF induces p53-mediated apoptosis through PPAR gamma signaling in human umbilical vein endothelial cells. Cardiovasc Res 76: 213-223.
109.Zhou XY, Liao Q, Pu YM, Tang YQ, Gong X, et al. (2009) Ultrasound-mediated microbubble delivery of pigment epithelium-derived factor gene into retina inhibits choroidal neovascularization. Chin Med J (Engl) 122: 2711-2717.

110. Gehlbach P, Demetriades AM, Yamamoto S, Deering T, Duh EJ, et al. (2003) Periocular injection of an adenoviral vector encoding pigment epitheliumderived factor inhibits choroidal neovascularization. Gene Ther 10: 637-646.

111. Gehlbach P, Demetriades AM, Yamamoto S, Deering T, Xiao WH, et al. (2003) Periocular gene transfer of sFlt-1 suppresses ocular neovascularization and vascular endothelial growth factor-induced breakdown of the blood-retinal barrier. Hum Gene Ther 14: 129-141.

112. Apte RS, Barreiro RA, Duh E, Volpert O, Ferguson TA (2004) Stimulation of neovascularization by the anti-angiogenic factor PEDF. Invest Ophthalmol Vis Sci 45: 4491-4497. 